\title{
GEOTECNOLOGIAS NA INVESTIGAÇÃO DE CONTRIBUIÇÃO PLUVIAL PARASITÁRIÁ EM REDE COLETORA DE ESGOTO
}

\author{
Vinícius de Oliveira Ribeiro ${ }^{1}$ \\ Antonio Conceição Paranhos Filho ${ }^{2}$ \\ Angélica Aparecida Dourado da Costa ${ }^{3}$
}

Resumo: No Brasil, o sistema de esgotamento sanitário predominantemente utilizado refere-se ao sistema de separador absoluto (somente captação de esgoto sanitário), por apresentar menor custo de implantação (menores diâmetros de rede) e oferecer mais flexibilidade de execução. Por outro lado, para o sucesso do sistema de separador absoluto, é necessário um eficiente controle para se evitar que a água pluvial, principalmente proveniente dos telhados e pátios, não seja encaminhada para o sistema de coleta. Como estes coletores não estão dimensionados para contribuição pluvial, extravasam pelos poços de visita, escoado pelas guias e sarjetas, podendo carrear doenças de veiculação hídrica à quem tiver contato com esta água. O presente estudo abrangeu a composição da base SIG, no software livre gvSIG 1.12, no município de Três Lagoas/MS, com foco no mapeamento dos pontos de extravasamento da rede coletora de esgoto em vias públicas. Tal procedimento permitiu avaliar a bacia de contribuição a montante do ponto de transbordamento e verificar a capacidade de escoamento da rede coletora a jusante, de forma a determinar as prováveis causas do evento. Com a caracterização de consumo das residências especializadas, ficou facilitada a análise da quantidade de esgoto gerado em sua bacia de contribuição, descartando a hipótese de que o coletor não tem capacidade de escoamento do mesmo, demostrando deste modo que a teoria de que os transbordamentos ocorrem devido às contribuições parasitárias.

Palavras Chave: Esgoto sanitário, extravasamento, geotecnologias, gvSIG, SIG.

Abstract: In Brazil, the sewage system predominantly used refers to the absolute separator system (only sanitary sewer catchment) due to lower cost of deployment (smaller network diameter) and offer more flexibility of implementation. On the other hand, for the success of the absolute tab system, a control strategy is required to prevent rainwater from roofs and particularly patios, isn't directed to the collection system. As these collectors are not sized to rain contribution, are outside the manhole, drained by curbs, can carry Toxoplasma gondii waterborne diseases to those who have contact with this water. This study covered the composition of the GIS base in the free software gvSIG 1.12 in Três Lagoas / MS, focusing on mapping the points of leakage of sewage disposal system on public roads. This procedure allowed evaluating the contribution basin upstream of the overflow point and checking the flow capacity of the collector downstream network, in order to determine the probable causes of the event. With the characterization of specialized consumer homes, was facilitated analysis of the amount of wastewater generated in contributing bowl, discarding the hypothesis that the collector has no flowability of the same, thereby demonstrating that the theory that overflows occur due to parasitic contributions

Key words: Sanitary sewer, extravasation, geotechnology, gvSIG, GIS.

\footnotetext{
${ }^{1}$ Universidade Estadual de Mato Grosso do Sul. E-mail: viniciusoribeiro@ yahoo.com.br

${ }^{2}$ Universidade Federal de Mato Grosso do Sul. E-mail: toniparanhos@gmail.com

${ }^{3}$ Instituto Federal de Ciência e Tecnologia do Mato Grosso. E-mail: angelica.dourado.jna@gmail.com
} 
O Brasil, com uma população de mais de 180 milhões de habitantes (IBGE, 2011), apresenta um imenso déficit de atendimento no que se refere ao esgotamento sanitário. Estima-se que, já ao final do século 20 , pouco mais de 44,5 $\%$ da população fosse atendida por sistema de coleta e afastamento de esgotos, sendo que menos de $37,9 \%$ da população tem esgoto tratado (BRASIL, 2010).

No Brasil, o sistema de esgotamento sanitário predominantemente utilizado refere-se ao de separador absoluto, por apresentar menor custo de implantação (menores diâmetros de rede) e oferecer mais flexibilidade de execução (TSUTIYA, 2006).

Os menores custos de execução permitem a ampliação do atendimento da população, permitindo vislumbrar a universalização e o acesso aos serviços de saneamento até 2030, conforme preconizado no Plano Nacional de Saneamento Básico Plansab (BRASIL, 2012).

Por outro lado, para o sucesso do sistema de separador absoluto, é necessário um eficiente controle para se evitar que a água pluvial, principalmente proveniente dos telhados e pátios, não sejam encaminhados para o sistema de esgoto (ARCEIVALA, 1981).

Como os coletores de esgoto sanitário não estão dimensionados para a contribuição pluvial, extravasam pelos poços de vista, escoando pelas guias e sarjetas, podendo causar doenças de veiculação hídrica, como a esquistossomose, amebíase e giardíase (COPASA, 2009).

Assim, há a necessidade de se analisar múltiplos critérios na verificação de pontos passíveis de contribuição pluvial (contribuição parasitária) de forma a agir preventivamente $\mathrm{e}$ corretivamente sobre o problema.

Os softwares SIG, além de terem capacidade de associação entre informações gráficas e alfanuméricas, são desenvolvidos para desempenhar funções específicas relacionadas a operações espaciais (MCKIBBEN, 1994). Mais de $75 \%$ dos dados de sistemas de abastecimento de água e de esgoto sanitário possuem características espaciais (localização). Os dados de interesse são referentes a infraestrutura implantada, uso e ocupação do solo e caracterização dos consumidores (FEINBERG, 1997).

\section{OBJETIVO}

Utilizando geotecnologias, elaborar uma técnica para o delineamento de bacia de contribuição de coletor de esgoto sanitário, de forma a investigar motivos para extravasamento frequente de esgoto doméstico em poço de visita em eventos pluviométricos.

\section{MATERIAIS E MÉTODOS \\ 3.1 Caracterização da área de estudo}

A área de estudo utilizada foi o Município de Três Lagoas/MS (Figura 1). Situado à margem esquerda do Rio Paraná, próximo a barragem da usina hidrelétrica de Jupiá. A região apresenta relevo suave e solo arenoso. Estas características específicas fazem com que coletores por gravidade, seja rede de esgoto ou drenagem, atinjam profundidades acima de 3,5 metros.

O município não dispõe, em sua totalidade, de rede de drenagem pluvial, e dada a sua topografia plana, observam-se diversos pontos de alagamento no perímetro urbanizado, cada vez mais agravados pela impermeabilização do solo (SANESUL, 2013).

Em diversas áreas, onde se observa os pontos de alagamento das ruas, os moradores abrem os poços de visita de esgoto - PV, para a água de chuva adentrar, fazendo com que nos pontos mais baixos dos coletores, as redes extravasem (Figura 2) e ou retornem nas ligações domiciliares, causando transtornos à população local. 


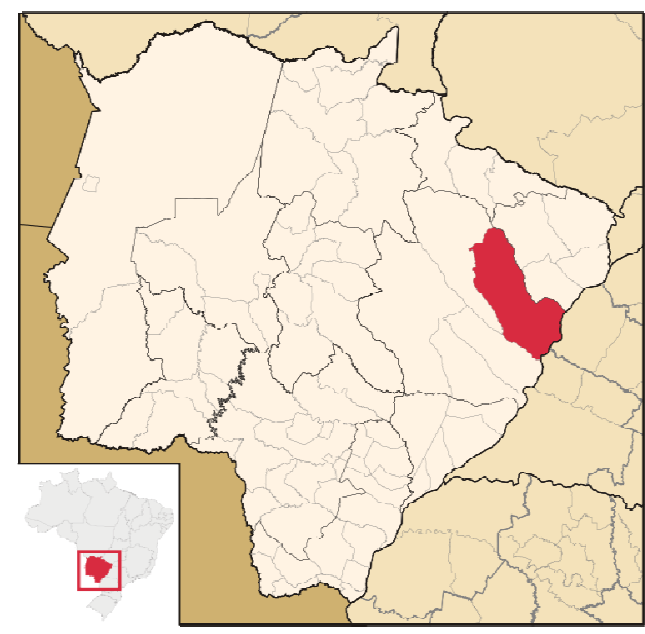

Figura 1 - Localização do município de Três lagoas/MS (ABREU, 2006).
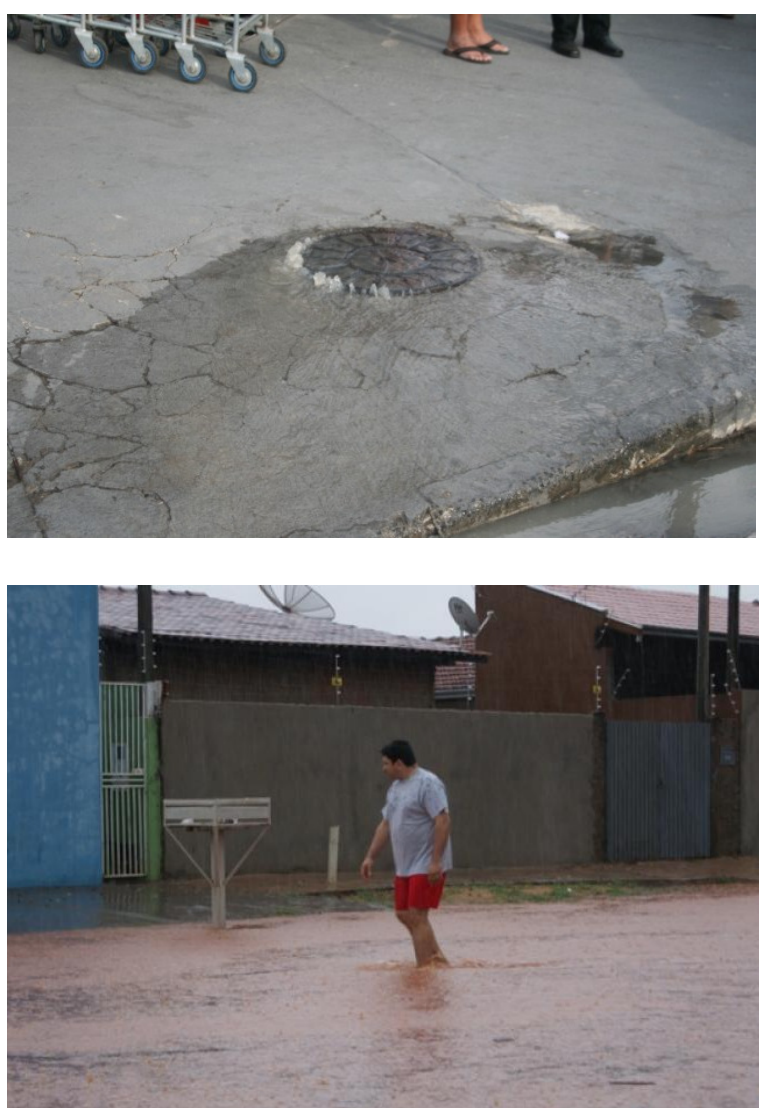

Figura 2 - Acima, poço de visita (PV) de esgoto transbordando na calçada. Abaixo, rua alagada nas proximidades da Lagoa Maior, em Três lagoas/MS. Fotos tiradas em 13 de fevereiro de 2012.

Selecionou-se um poço de visita de esgoto que tem transbordado frequentemente em períodos chuvosos, sendo alvo de reclamação constante dos moradores da região. Ele se encontra na junção da Rua Oliveira com Rua Tomas da Costa, próximo da Lagoa Maior (Figura 3). A rede coletora ao qual está inserido loca-se a montante da estação elevatória de esgoto sanitário bruto Difusora.
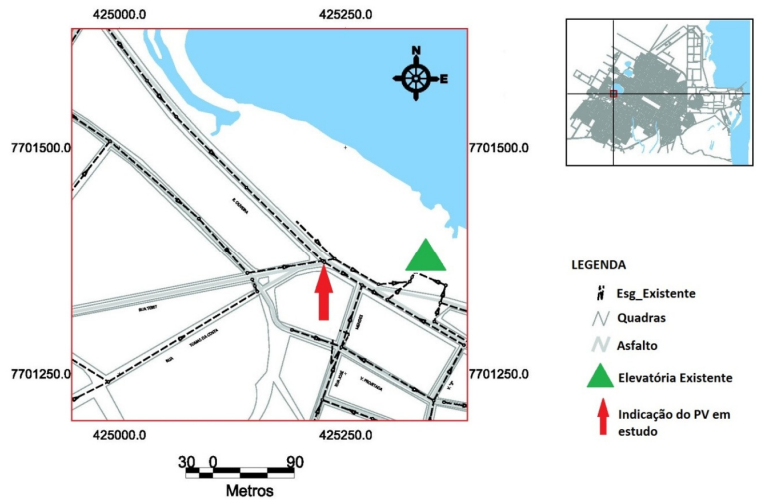

Figura 3 - Localização do PV em estudo, em Três Lagoas/MS.

\subsection{Obtenção de Dados}

\subsubsection{Arquivos vetoriais}

As informações de planialtimétria (ruas, quadras, interferências, rede de esgoto, rede de água, rede de drenagem, rede de energia e topografia) foram obtidas junto ao acervo da SANESUL, em formato $\mathrm{dwg}$ (padrão $\mathrm{CAD}$ ). Os arquivos foram tratados inicialmente em DraftSight (DASSAULT, 2011), dividindo cada informação em camada distinta (layer) para posterior introdução em ambiente SIG (Figura 4). Os dados foram georreferenciados em gvSIG (VALENCIANA, 2012), utilizando o datum oficial brasileiro, o SIRGAS 2000.

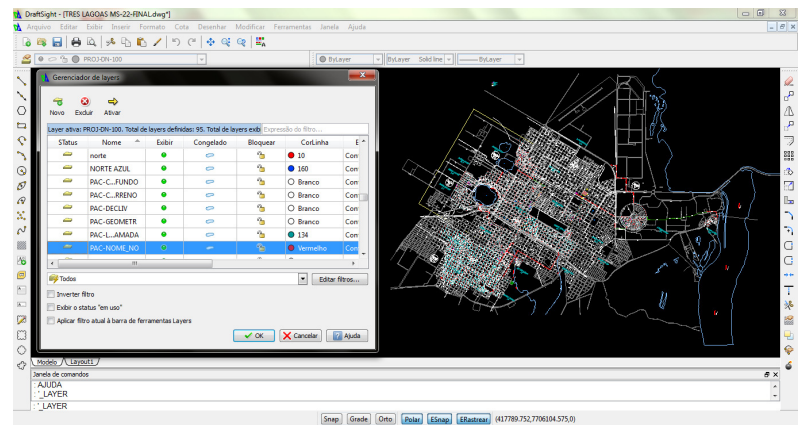

Figura 4 - Vista do Gerenciador de layers dos arquivos vetoriais de Três lagoas/MS.

Após a composição do SIG efetuou-se o traçado da bacia de contribuição à montante do PV em estudo. A bacia de contribuição delimitada no SIG foi traçada com auxilio do gvSIG, através da ferramenta 
watershed presente na extensão Sextante. O método de cálculo da direção de fluxo utilizado foi o D8, que consiste em determinar a direção de maior declividade de um pixel/célula em relação a seus 8 pixels vizinhos. Segundo Paranhos Filho et al. (2008), a direção de fluxo D8 tem a finalidade de estruturar uma grade onde o valor de cada pixel representa a direção do escoamento da água, sempre do pixel vizinho de maior valor de altitude para o de menor valor de altitude.

O levantamento topográfico, efetuado nos cruzamentos das vias e em pontos notáveis de picos e/ou vales na área de estudo, auxiliou na delimitação com maior precisão da bacia de captação. Foram necessárias pequenas adequações, em função de redes coletoras existentes na extremidade da bacia, que quando da sua execução, foram direcionadas para outro coletor, não contribuindo para a seção em estudo.

\subsubsection{Ligações domiciliares}

A SANESUL dispõe de cadastro dos usuários, em planilha eletrônica, com históricos de consumo e número de residências. Este acervo não se encontrava georreferenciado. Para efetuar tal procedimento de georreferenciamento elaborou-se um dicionário de dados contendo o nome da rua e o número da residência. Este foi carregado no software SIG gvSIG Mobile, instalado no hardware GPS Trimble Juno SB, com sistema operacional Windows Mobile 6.0.

Com o auxílio do receptor GPS cadastraram-se as coordenadas geográficas relacionadas ao número das residências. Esta etapa teve duração de seis meses (janeiro a junho de 2012). A informação das ligações é fundamental para determinação do volume real de esgoto que contribui na seção de extravasamento.

$\mathrm{Na}$ sequência, atrelaram-se as informações das coordenadas geográficas ao cadastro das residências para anexar ao banco de dados SIG. Com a ferramenta Count points in polygons efetuou-se a quantificação das ligações existentes no interior da bacia de contribuição delimitada

\subsection{Verificação hidráulica dos Condutores}

De forma a caracterizar a capacidade de escoamento da tubulação, efetuou-se uma análise da capacidade de escoamento do trecho a jusante da bacia de contribuição, afluente da estação elevatória de esgoto bruto existente (Figura 5).

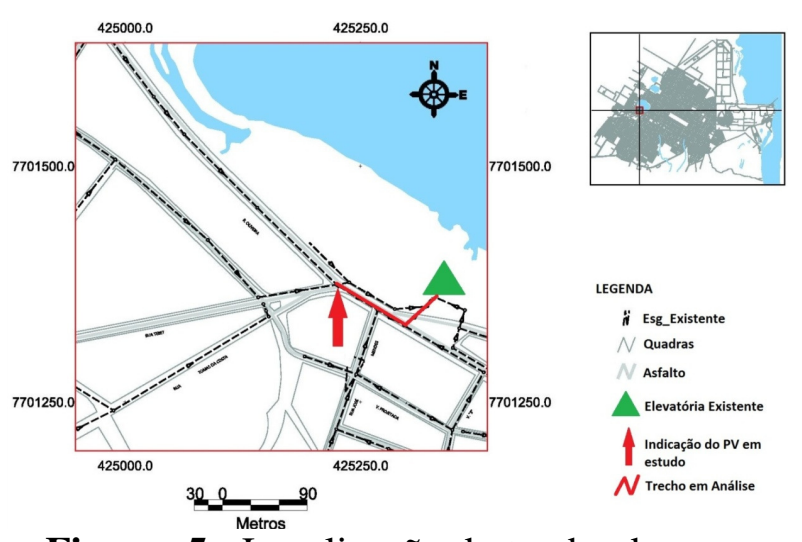

Figura 5 - Localização do trecho de tubulação coletora de esgoto em análise.

$\mathrm{Na}$ verificação da vazão e esgoto bruto oriundo da bacia de contribuição utilizou-se a equação de dimensionamento de vazões de esgoto usualmente empregada no projeto de coletores para esgoto (TSUTIYA \& SOBRINHO, 2011).

$$
\bar{Q}_{f}=\frac{C \cdot P_{f} \cdot q_{f}}{86400}
$$

Onde:

$\bar{Q}_{f} \quad=$ Vazão máxima de esgoto

doméstico, expresso em

litros/segundo/habitante (1/s);

$\mathrm{K}_{1} \quad=$ coeficiente de máxima vazão

diária, 1,2;

$\mathrm{K}_{2}=$ coeficiente de máxima vazão

horária, 1,5;

$\mathrm{C}=$ coeficiente de retorno de água

para esgoto, 0,8 ;

$\mathrm{P}_{\mathrm{i}}, \mathrm{P}_{\mathrm{f}}=$ população inicial e final, em número de habitantes;

$\mathrm{q}_{\mathrm{i}}, \mathrm{q}_{\mathrm{f}}=$ consumo de água efetivo per capita inicial e final, (Litros/habitante ao dia). 
$\mathrm{Na}$ verificação da capacidade de escoamento do coletor a jusante à do PV em estudo foi empregado o conceito de raio hidráulico-RH, parâmetro importante no dimensionamento

de canais, dutos, tubos e outros componentes das obras hidráulicas, sendo comumente usado para se estimar o raio de tubos e canais com seção transversal não-circular (PORTO, 2006).

Determinou-se inicialmente o fator hidráulico (Equação 2), em função da declividade, diâmetro e rugosidade da tubulação existente, bem como vazão de esgoto calculada (PORTO, 2006).

A lâmina máxima de esgoto na vazão de final de plano não deve ser superior a $75 \%$ do diâmetro do coletor (ABNT, 1986).

$$
F H=\frac{Q x n}{D^{\frac{8}{3}} x I^{\frac{1}{2}}}
$$

Onde:

$$
\begin{aligned}
& \mathrm{FH} \quad=\text { Fator Hidráulico; } \\
& \mathrm{Q} \quad=\text { Vazão }\left(\mathrm{m}^{3} / \mathrm{s}\right) ; \\
& \mathrm{n} \quad=\text { coeficiente de rugosidade de } \\
& \text { Manning; } \\
& \mathrm{D} \quad=\text { Diâmetro da tubulação }(\mathrm{m}) ; \\
& \mathrm{I} \quad=\text { Declividade do trecho }(\mathrm{m} / \mathrm{m}) .
\end{aligned}
$$

As verificações foram feitas simulando a vazão de esgoto doméstico quantificado (equação 1), somada a contribuição linear por metro de rede oriunda de infiltração de água do subsolo na tubulação, denominada de taxa de contribuição de infiltração. $\mathrm{O}$ valor para esta taxa foi determinado pela média do intervalo sugerido pela norma NBR 9649/1986 (0,05 a $1,0 \mathrm{l} / \mathrm{s} \times \mathrm{km})$, sendo adotado $0,525 \mathrm{l} / \mathrm{s} \mathrm{x} \mathrm{km}$. A quantidade de rede na bacia de contribuição foi obtida no SIG composto.

Por fim, simulou-se também a vazão oriunda de uma precipitação de 1 $\mathrm{mm} / \mathrm{h}$ para caracterização do impacto desta no coletor em análise.

\section{RESULTADOS E DISCUSSÃO}

A bacia de contribuição delimitada (Figura 6) apresenta declividade predominante em direção à Lagoa Maior. Como apresentado no SIG, as vias encontram-se pavimentadas e não há rede de drenagem. Os valores de área e perímetro $(64,23$ ha e $3,22 \mathrm{~km})$ são fornecidas pelo gvSIG apresentadas na Figura 7.

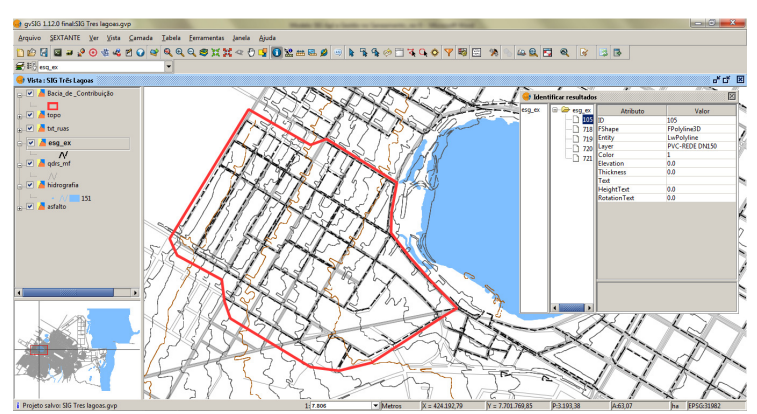

Figura 6 - Vista do SIG Três Lagoas, com destaque para a bacia de contribuição delimitada.

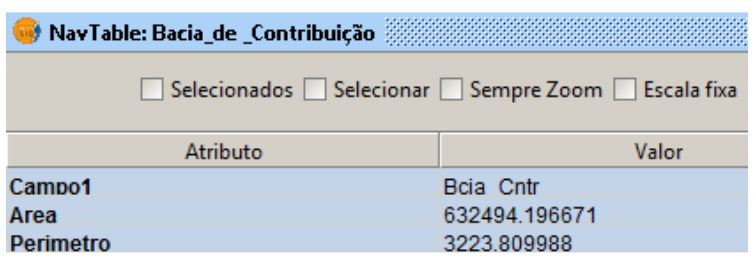

Figura 7 - Valores de área $\left(\mathrm{m}^{2}\right)$ e perímetro $(\mathrm{m})$ da bacia de contribuição delimitada, extraídas do gvSIG.

Obteve-se um total de 874 (oitocentos e setenta e quatro) economias. Adotando a média de moradores por domicílio ocupado para Três Lagoas/MS, sendo de 3,2 (IBGE, 2011), teremos uma população na bacia de contribuição estimada em cerca de 2.797 pessoas. Pelo histórico de consumo das mesmas, chegou-se a um consumo per capita de água de 130,3 1/habitante $\mathrm{x}$ dia (1/hab $\mathrm{x}$ dia). Para verificação das vazões de final de plano, trinta anos a partir da instalação da rede (2022), utilizou-se o valor de 180 1/hab. $x$ dia de maneira mais restritiva.

Inserindo os valores na Equação 1, termos uma vazão de esgoto doméstico máxima na bacia na ordem de 8,4 1/s. $\mathrm{Na}$ bacia, temos um total de, aproximadamente, $16 \mathrm{~km}$ de redes coletoras. Empregando-se a taxa de 
infiltração estipulada, teremos uma vazão de contribuição de infiltração de $0,8 \mathrm{l} / \mathrm{s}$. No total, somados a vazão de esgoto doméstica e a vazão de infiltração, tem-se uma vazão total máxima de esgoto na seção estudada de $9,21 / \mathrm{s}$ ou $0,0092 \mathrm{~m}^{3} / \mathrm{s}$.

$\mathrm{O}$ trecho em análise tem declividade de $0,0037 \mathrm{~m} / \mathrm{m}$, extensão de 123,52 metros e diâmetro de $0,25 \mathrm{~m}$. O material da tubulação é de PVC e o coeficiente de Manning (n) adotado foi o de 0,013 . De posse dos dados, na equação 2 , obteve-se o valor de $\mathrm{FH}=0,079$. Obtém deste modo os respectivos valores de $\mathrm{RH}=0,0695 \mathrm{e} \mathrm{Y} / \mathrm{D}=0,11$. Deste modo, somente $11 \%$ do diâmetro da tubulação está preenchido para a vazão estimada, descartando a possibilidade de o coletor estar subdimensionado, e sem capacidade de transportar o efluente até à estação elevatória.

Simulando uma precipitação de 1 $\mathrm{mm} / \mathrm{h}$ na área da bacia $(63,25 \mathrm{ha})$, teremos uma vazão de $175,7 \quad 1 / \mathrm{s}$ ou $0,1757 \mathrm{~m}^{3} / \mathrm{s}$. Vazão dezenove vezes maior que a vazão total máxima de esgoto calculada. Inserindo este valor de vazão na equação 2 , teremos um $\mathrm{FH}=$ 1,061. O valor máximo de FH é na ordem de 0,3117, representando um tubo de circular a seção plena (Y/D = 1). Por tal, o valor de FH calculado nestas condições caracteriza a não capacidade de escoamento, ou seja, o transbordamento do coletor, demonstrando sua incapacidade de escoar contribuições pluviais, haja vista ter sido dimensionado pelo conceito de separador absoluto.

Um telhado de habitação padrão popular com $100 \mathrm{~m}^{2}$ de área, para a chuva estudada, incide numa vazão de 0,0278 1/s. Uma residência com 3 moradores e com consumo de água na ordem de 180 1/hab. x dia, representa uma vazão de esgoto de 0,009 1/s. Ou seja, só a água proveniente de um só telhado é 3 vezes maior que a da residência. Caso a caneleta deste estiver interligada a rede pública de esgoto há o risco de extravasamento da mesma.

A conscientização da população é fundamental para evitar tais transtornos. Até mesmo porque o efluente extravasado pode veicular, além de danificar a infraestrutura do sistema de coleta, transporte e tratamento de esgoto, que não estão preparados para receber contribuições desta magnitude.

\section{CONCLUSÃO}

A composição do SIG e a espacialização de informações foram de grande valia para avaliação e análise do problema em estudo de maneira espacializada. A disponibilidade das informações num banco georreferenciado possibilitou a avaliação sob um enfoque de múltiplos critérios, tais como o uso e ocupação do solo, número de economias, área contribuinte e fatores ambientais.

Comprovou-se a magnitude que uma contribuição pluvial parasitária pode atingir em coletor de esgoto doméstico dimensionado por conceito de separador absoluto, bem como a necessidade de conscientização dos moradores quanto ao tema, por se tratar de saúde coletiva e bem comum.

O estudo pode servir de base para avaliação de outros pontos críticos no sistema, haja vista o SIG já composto. Também para definições de regiões passíveis de monitoramento e ou ações concentradas de educação ambiental, a fim de reduzir as ocorrências de impactos ambientais negativos.

Por fim, o gvSIG 1.12, software livre e gratuito, apresentou-se estável em todas as funções demandadas. Sua interface é bastante intuitiva, assim como sua interpolaridade com diversos formatos de arquivos raster e vetoriais, o que permiti uma boa desenvoltura nos trabalhos efetuados, atendendo plenamente as demandas do estudo.

Sugere-se em novos estudos efetuar uma segmentação de imagem em alta resolução da bacia de contribuição, de forma a elaborar um mapa de uso e ocupação do solo na mesma, de forma a nortear órgãos fiscalizadores, em vistoria de áreas criticas, com elevado grau de impermeabilização do solo. 


\section{REFERÊNCIAS}

ABNT, Associação Brasileira de Normas Técnicas. (1986). NBR 9649 - Projeto de redes coletoras de esgoto sanitário. Rio de Janeiro: RJ.

ABREU, R. d.(2006). Map locator of Mato Grosso do Sul's city. Wikipédia, a enciclopédia livre. Disponível em < http://pt.wikipedia.org/wiki/Ficheiro:Mat oGrossodoSul_MesoMicroMunicip.svg> . Acesso em 10 de dezembro de 2012.

ARCEIVALA, S. J. (1981). Wastewater treatment and disposal. New York: Marcel Dekker.

BRASIL. (2012). Plano Nacional de saneamento Básico. Disponível em: < http://www.brasil.gov.br/noticias/arquivo s/2012/08/14/brasil-quer-universalizarservico-de-saneamento-basico-ate-2030>. Acesso em 12 de outubro de 2012.

BRASIL. (2010). Sistema Nacional de Informações Sobre o Saneamento - SNIS. Disponível em:< http://www.snis.gov.br/>. Acesso em 03 de outubro de 2012.

COPASA, Á. d. (2009). Doenças de veiculação hídrica. Disponível em $<$ http://www.copasa.com.br/media2/Pesq uisaEscolar/COPASA_Doen\%C3\%A7as. pdf $>$. Acesso em 23 de março de 2012.

DASSAULT, D. S. (2011). DraftSight. software. Disponível em: < http://www.3ds.com/products/draftsight/o verview/>. Acesso em 19 de março de 2012.

FEINBERG, D. (1997). Integrating GIS With Water and Wastewater Hydraulic Models. ESRI.
IBGE, Instituto Brasileiro de Geografia e Estatistica. (2007). Sistema Geodésico Brasileiro: Banco de Dados Geodésicos. Disponível em: $<$ http://www.bdg.ibge.gov.br/bdg/pdf/rel atorio.asp?L1=93542>. Acesso em $12 \mathrm{de}$ novembro de 2012.

IBGE. Instituto Brasileiro de Geografia e Estatistica. (2011).. Dados Históricos dos Censos. disponível em $<$ http://www.ibge.gov.br/home/estatistica /populacao/censohistorico/default_hist.sh tm> . Acesso em 28 de 12 de 2010

MCKIBBEN, W. (1994). Wastewater Collection System Plannig With GIS in a Large System. Urisa.

PARANHOS FILHO, A. C., LASTÓRIA, G., \& TORRES, T. G. (2.008). Sensoriamento Remoto Ambiental Aplicado: Introdução as Geotecnologias. Campo Grande, MS, Brasil: UFMS.

PORTO, R. d. (2006). Hidráulica Básica ( $4^{\mathrm{a}}$ ed.). São Carlos, SP: EEESC USP.

SANESUL, Empresa de Saneamento de Mato Grosso do Sul (2013). Relatório técnico de viagem.PROEG/GEPRO. Campo Grande MS, Brasil: ABES.

TSUTIYA, M. T. (2006). Abastecimento de àgua ( $4^{\mathrm{a}}$ ed.). São Paulo, SP, Brasil: ABES.

TSUTIYA, M. T., \& SOBRINHO, P. A. (2011). Coleta e Transporte de Esgoto Sanitário ( $3^{\mathrm{a}}$ ed.). Rio de Janeiro, RJ: ABES.

VALENCIANA, G. (2012). Conselleria d'Infraestructures $i$ Transport. gvSIG versão 1.12. Disponível em: $<$ http://www.gvsig.org/web/>. Acesso em 15 de março de 2012. 